\title{
Sex Differences in Ability to Recognize Family Resemblance
}

\author{
Randolph M. Nesse \\ University of Michigan Medical Center, Ann Arbor, Michigan
}

Andrew Silverman

Department of Psychology, University of Texas, Austin, Texas

\author{
Alan Bortz \\ School of Medicine, University of Pittsburgh, Pittsburgh, Pennsylvania
}

In order to test the different expectations of evolutionary psychologists and "folk" psychologists about whether men or women are better at judging family resemblance, we created a test consisting of pairs of photographs, some of a parent and that parent's child, and some of an unrelated parent and child. Two hundred subjects judged the relatedness of 24 pairs of photos. The results show women and men to be equal in ability to judge family resemblance (mean number correct 14.99 versus $14.53, F=$ $1.7, p=0.19$ ). Both sexes were better able to judge resemblance for mothers than fathers $(F=11.25, p<0.0001)$, and men and women were better at judging relatedness for children of their own sex $(F=3.99, p<0.05)$, Ability to judge family resemblance was not related to the rater's age, marital status, number of siblings, number of children, or years of education. On a test of ability to recall faces, women were superior $(F=4.14, p<0.043)$. These findings are considered in relationship to previous research and to the predictions of evolutionary and folk psychology.

KEY WORDS: Kin recognition; Family resemblance; Face recognition; Visual recognition; Photographs; Sex differences; Evolution; Natural selection; Evolutionary psychology.

Received March 6, 1989; revised September 12, 1989.

Address reprint requests to: Randolph M. Nesse, M.D., University of Michigan Medical Center, Med-Inn Building, Room C440, Ann Arbor, MI 48109-0840. 


\section{INTRODUCTION}

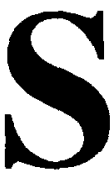

ociobiology has been criticized for making few testable predictions that differ from those made by "folk psychology" (Kitcher 1985). Making such predictions is not easy, however, because human intuition is not merely a competing theory but a capacity shaped by natural selection. As Symons (1987) put it, "Folk psychology is the toughest kid on its block." Nonetheless, scientific theories are powerful only to the extent that they make predictions that aren't already obvious predictions. After a search for an unstudied question about which folk and evolutionary psychologists might make opposite, testable predictions, we decided to study sex differences in the ability to recognize family resemblance between parents and children. We expected that folk psychologists would predict that women would do better on this task, while evolutionary psychologists would predict that men would do better. These expectations were confirmed. Of people randomly approached at an outdoor art fair, 64 out of 65 said they thought women would be superior at guessing if pairs of photographs were of a related or unrelated adult and child. Most of those who could give a reason for their prediction made reference to the belief that women tend to be better than men at social tasks. The predictions of participants in an evolutionary psychology conference were different. When asked, "Would you predict that man are better, worse, or the same as women at the task of judging the relatedness of adults and children from photographs?" 13 out of 19 said they thought that men would do better than women. When asked why they made that prediction, most referred to the problem of paternity confidence and said that men with a superior ability to recognize their children by phenotypic clues might have an advantage, especially when the risk of being cuckolded is high. Our more considered prediction was similar. Natural selection might or might not have shaped a specialized ability to recognize kin, and this ability might or might not be sexually dimorphic, but if a sex difference in this ability exists, it should be in favor of men, because paternity uncertainty results in benefits to men from this ability that are not available to women. Thus, a sex difference in ability to recognize family resemblance is not a necessary result of natural selection, but if a difference exists, it should favor men. This prediction based on evolutionary theory is of special interest because it is the opposite of that made by "folk psychologists."

The question of possible sex differences in ability to recognize family resemblance between parents and children is a natural extension of current research in evolutionary psychology. First, Hamilton's discovery of kin selection (1964) has led to growing recognition of the fitness benefits of the ability to distinguish kin from nonkin and to substantial new efforts to discover the mechanisms that make this possible (Holmes and Sherman 1983). Second, evolutionary psychology expects the brain to be sexually dimorphic (Symons 1989), and sex differences in certain preferences and abilities have 
been a research focus (Buss 1988; Daly and Wilson 1983; Symons 1979). Third, evolutionists have long emphasized the special adaptive importance for males of knowing which children are theirs and which are not (Alexander 1974; Daly and Wilson 1982a). This may explain why mothers and relatives distort their perceptions, or at least their reports, to emphasize the resemblance of babies to fathers rather than mothers. (Daly and Wilson 1982b). Fourth, the search for the evolved cognitive mechanisms that regulate behavior (Barkow 1989; Cosmides and Tooby 1989; Symons 1989) gives further impetus, because several lines of evidence suggest that the capacity to recognize family resemblance could be a model Darwinian algorithm.

The general ability to recognize faces is very similar to the ability to recognize family resemblance and was identified early as a specialized cognitive capacity (Bodamer 1947). One bit of everyday evidence is the remarkable ability of people to recognize faces even years after a brief encounter. Also, patterns of memory retention for faces are distinct from those for landscapes, nouns, and simple objects (Deffenbacher et al. 1981), and familiar faces can be recognized even after most of the information is lost by blurring (Harmon 1973). Further support is provided by evidence that young children use only a few salient features to recognize faces and show no advantage in recognizing upright (versus inverted) faces, until the age of 10-12 years, when recognition begins to depend on Gestalt patterns (Diamond and Carey 1977).

Perhaps the best evidence for a specialized capacity for recognizing faces comes studies of prosopagnosia. Patients with this neurological condition can describe faces accurately but cannot recognize their friends until they speak (Hecaen and Angelergues 1962). Benton (1980) notes that there are two distinct patterns of prosopagnosia that suggest the existence of two distinct capacities. Patients with a localized right posterior brain lesion cannot discriminate unfamiliar faces, while some patients with bilateral occipital lesions have an isolated deficit in ability to recognize familiar faces. These patients cannot distinguish familiar and unfamiliar faces, but they do have unconscious autonomic responses to familiar faces (Tramel and Damascio 1985).

There is additional evidence for the anatomic localization of this capacity. A deficit in facial recognition ability occurs after right-sided, but not left-sided, electroconvulsive therapy (Berent 1977). Also, people who are better at recognizing faces presented to the left visual ficld (right cercbral hemisphere) are better at the task than those who are better able to recognize faces presented to the right visual field (Ross-Kossak and Turkewitz 1984). The ability to recognize faces has a bimodal distribution for girls over age 12 and for adult women, especially those with a left visual field advantage (Turkewitz and Ross-Kossak 1984). A few women seem to have superior facial recognition ability whose mechanism is located in the right hemisphere. The ability of women to recognize faces is superior to men in five studies and the same in ten other studies, but both sexes are better at rec- 
ognizing members of their own sex (McKelvie 1981). The only previous study of the ability to recognize family resemblance from facial characteristics showed that adults could guess which of four photographs of babies went with the actual mother with better than chance accuracy. Sex differences were not a focus of this study, but women were correct in $38 \%$ and men in $31 \%$ of guesses, a statistically nonsignificant difference (Porter et al. 1984).

Taken together, these findings strongly imply the existence of a specialized, anatomically localized, and sexually differentiated Darwinian algorithm for recognizing faces. This increases the possibility that a related algorithm might facilitate recognition of parent-child resemblance, and, thus, the possibility that male and female ability to recognize family resemblance might well differ.

\section{METHODS}

Indoor photographs were taken of over 200 Caucasians, using the same camera, flash, background, distance to subject, and type and speed of color film. All photographs were of individual parents and their children ages 6 months to 18 years. In all cases, parents said that the children were their own natural children. There was no independent way to confirm these statements. but confidence was increased somewhat because the experimenters had known most subjects for many years. In order to minimize extraneous cues, all photographs were reprinted by the same photographic laboratory and were trimmed so only the head and neck were visible. A randomization process was used to create 80 initial test items: Half were pairs of photographs of an actual parent and that parent's child, the other half were photographs of an unrelated parent and child that had been paired by a random process. The 80 items were mounted in a scrapbook. Subjects for this preliminary study $(N=100)$ were recruited in public places and were asked to mark "Yes" or "No" on an answer sheet to indicate their best guess as to whether the people in the photographs were related. All said they did not know any of the people in the photographs. Overall, $67 \%$ of these responses were correct.

The results of this preliminary study were used to choose 24 items for the final test. The final test was divided into four subsections (six items each) that are designated, for convenience, "father/daughter, father/son, mother/ daughter, mother/son" even though the photographs were of related people in only half the items. In order to select those photo pairs that best discriminated high scorers from low scorers, test items were ranked according to the point-biserial correlation between the correct score on that item ( 0 or 1$)$ and the individual total number correct. The three highest ranked items that showed a related pair and the three highest ranked items that showed an unrelated pair were selected for each subsection, with exclusion of seven items on which over $90 \%$ or less than $50 \%$ of raters were correct. The 24 
final items were arranged in a scrapbook in random order. Eight additional single photos were added at the end of the test to assess the ability to recall faces. Four of these had been seen before in the test book; four had not. Demographic questions were also asked at the end of the test.

Two research assistants, who were blind to the correct answers, obtained data from over 200 subjects. Subjects were motivated by a prize of $\$ 50$ for the best score and another $\$ 50$ prize randomly awarded to someone with a score in the top $50 \%$. Subjects were approached in a variety of settings; approximately equal numbers of men and women were sampled in each setting and time period. A standardized set of instructions was read to potential subjects. Subjects were not told about the proportion of items that showed related people. Answers were recorded as check marks in "Yes" and "No" boxes. There was no time limit, but subjects were not allowed to return to an item they had already completed. Completion of the test usually took about 10 minutes. Approximately half the sample consisted of students, most of whom were approached in their dormitory rooms or while waiting in movie or registration lines. Most of the older subjects were approached at their homes or at a shopping center. Data from subjects who appeared drunk, ill, or noncooperative were discarded before scoring. Raw data were entered into a microcomputer spreadsheet for initial processing and were transferred into a statistics program for further analysis. Data from three outliers was discarded: one had only five items correct, one guessed that all pairs but one were related, and one guessed that all pairs but two were unrelated. A three-way nested analysis of variance (ANOVA) was performed on the number of items correct using the multilinear general linear hypothesis module from the SYSTAT computer program, with a betweensubjects variable of sex of rater and within-subjects variables of sex of parent and sex of child in the photographs.

\section{RESULTS}

The 200 subjects included 92 men and 108 women ranging in age from 15 to 78 years $($ mean $=30.0, S D=14.8)$. They had a mean of $3.1(S D=2.3)$. years of education after high school, $2.2(\mathrm{SD}=1.7)$ siblings, and 75 ( $\mathrm{SD}$ $=1.25$ ) children. The number of correct items ranged from 7 to 22 with a distribution that was approximately normal (Fig. 1). Raters had a mean of $14.78(\mathrm{SD}=2.48)$ items correct, and $91 \%$ of raters were correct on 12 or more items. The mean was significantly different from that expected by chance $(t=14.78, p<0.0001)$. Correlations between correct answers on individual items and total number of correct answers ranged from .042 to .369 with a mean of $.221(\mathrm{SD}=.086)$. Of the 24 main items, 21 had items versus total score correlations significantly $(p<0.05)$ greater than chance. The mean of item versus total correlations did not differ significantly in the four subgroups. The mean age of the children in the photographs was not 


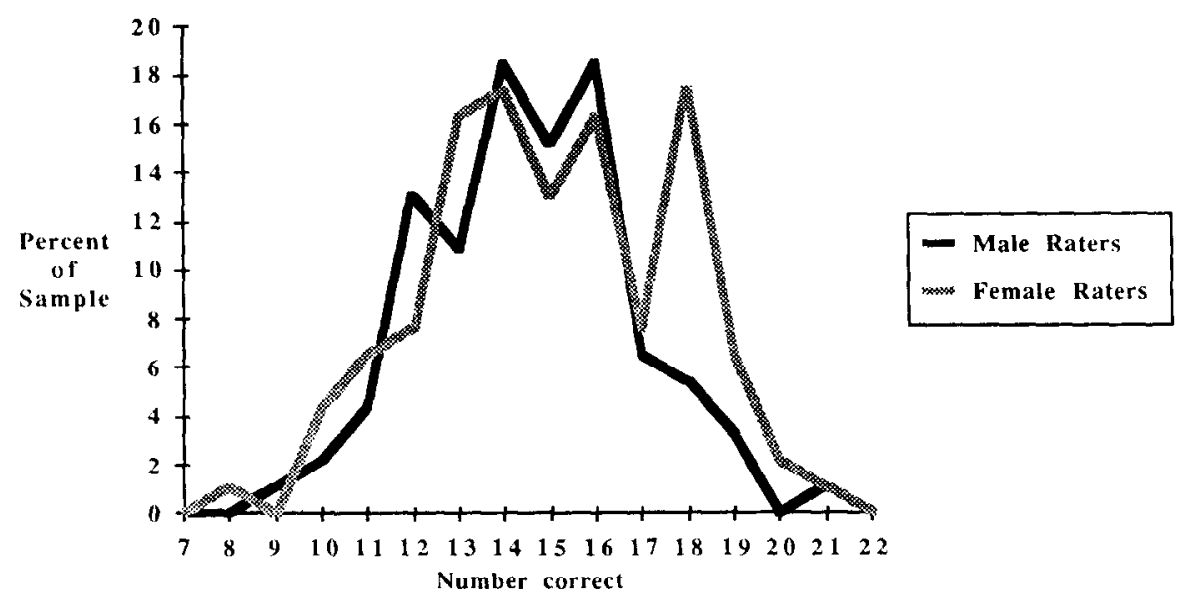

FIGURE 1. Frequency distribution of number correct by sex of rater.

significantly different in the four subgroups, and there was no trend for a correlation between number correct on an item and the age of the child in that item.

The main ANOVA (Table 1) showed no significant main effect for sex of rater. With alpha set at $5 \%$, the design was capable of detecting a $10 \%$ difference in ability to judge family resemblancce with a power (1- $\beta$ ) of $90 \%$. A frequency distribution of the scores by sex of rater (Fig. 1) shows matching distributions, except that the distribution for women was bimodal because $23.2 \%$ of women (but only $10.9 \%$ of men) had very high scores of 18 or more.

Tahle 1. Analysis of Variance of Total Number Correct as a Function of Sex of Rater, Sex of Parent, and Sex of Child

\begin{tabular}{|c|c|c|c|c|c|}
\hline & SS & $d f$ & MS & $F$ & $p$ \\
\hline \multicolumn{6}{|l|}{ Between subjects } \\
\hline Sex of rater & 2.61 & 1 & 2.61 & 1.70 & 0.194 \\
\hline Error & 304.47 & 198 & 1.54 & & \\
\hline \multicolumn{6}{|l|}{ Within subjects } \\
\hline Sex of parent & 14.54 & 1 & 14.54 & 11.25 & $<0.001$ \\
\hline Error & 255.91 & 198 & 1.29 & & \\
\hline Sex of child & 0.21 & 1 & 0.21 & 0.17 & 0.681 \\
\hline Error & 244.17 & 198 & 1.23 & & \\
\hline Sex of rater $\times$ sex of parent & 0.01 & 1 & 0.01 & 0.01 & 0.934 \\
\hline Error & 255.91 & 198 & 1.29 & & \\
\hline Sex of rater $\times$ sex of child & 4.92 & 1 & 4.92 & 3.99 & 0.047 \\
\hline Error & 244.17 & 198 & 1.23 & & \\
\hline Sex of parent $\times$ sex of child & 1.82 & 1 & 1.82 & 1.39 & 0.240 \\
\hline Error & 258.68 & 198 & 1.31 & & \\
\hline Sex of rater $\times$ parent $\times$ child & 0.01 & 1 & 0.01 & 0.01 & 0.925 \\
\hline Error & 258.68 & 198 & 1.31 & & \\
\hline
\end{tabular}




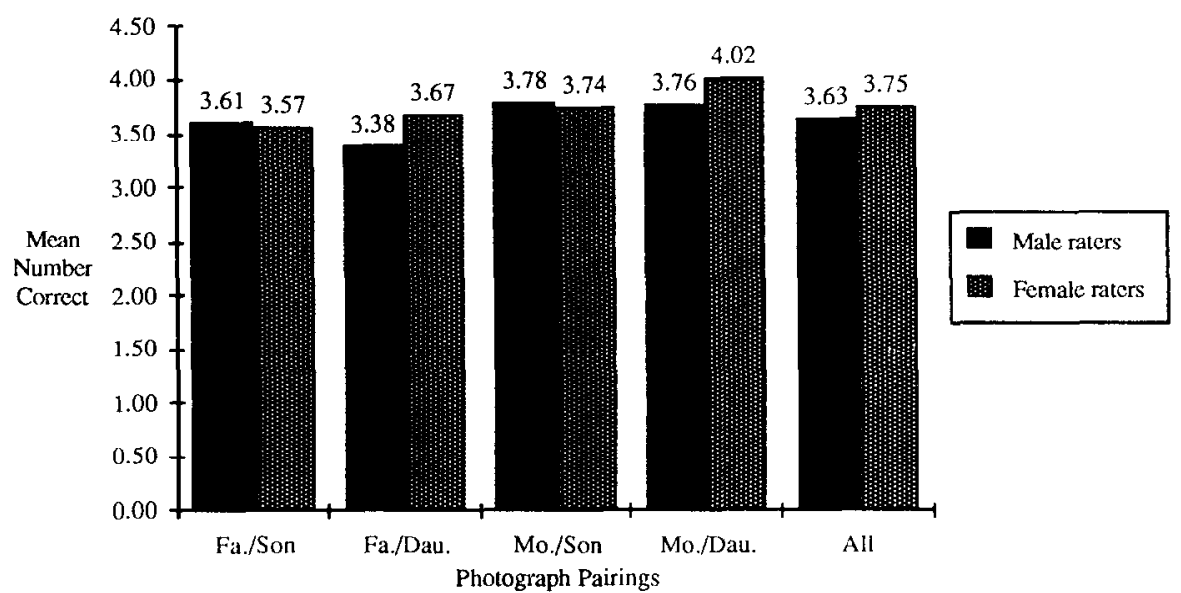

FIGURE 2. Mean number correct by sex of rater for the four subgroups.

Any difference between the overall populations of women and men must be small, but a few women may have superior ability to recognize family resemblance.

Differences in scores in the four subgroups of photographs were small (Fig. 2). Pairs of photos that included a mother were easier to judge than those that included a father $(F=11.25, d f=1,198, p<0.001)$, but no similar effect was observed for sex of child. Sex of rater interacted significantly with sex of child $(F=3.99, d f=1,198, p<0.05)$; men are better at judging the relatedness of sons than daughters, and women are better at judging the relatedness of daughters than sons (Fig. 3a). There was no trend towards a similar interaction between sex of rater and sex of parent (Fig. 3b).

Table 2 shows the relationship of other variables to sex of rater and total number correct. Men and women raters differed only on years of education and the ability to distinguish familiar from unfamiliar faces. Women

Table 2. Relationships Among Sex of Rater, Number Correct, and Other Variables

\begin{tabular}{|c|c|c|c|c|c|c|c|}
\hline \multirow[b]{3}{*}{ Variable } & \multicolumn{4}{|c|}{ Sex Differences } & \multicolumn{3}{|c|}{$\begin{array}{c}\text { Correlation with Number } \\
\text { Correct }\end{array}$} \\
\hline & \multicolumn{2}{|c|}{ Mean Values } & \multirow[b]{2}{*}{$F$} & \multirow[b]{2}{*}{$p$} & \multirow[b]{2}{*}{$r$} & \multirow[b]{2}{*}{$r^{2}$} & \multirow[b]{2}{*}{$p$} \\
\hline & Men & Women & & & & & \\
\hline Age (years) & 29.6 & 28.4 & 0.318 & 0.573 & -0.056 & 0.003 & 0.428 \\
\hline Number of children & 0.74 & 0.75 & 0.004 & 0.951 & 0.000 & 0.000 & 0.999 \\
\hline Number of siblings & 2.06 & 2.22 & 0.436 & 0.510 & 0.091 & 0.008 & 0.200 \\
\hline $\begin{array}{l}\text { Education (years } \\
\text { college) }\end{array}$ & 2.70 & 3.70 & 10.1 & 0.002 & -0.049 & 0.002 & 0.460 \\
\hline Yes answers & $52.4 \%$ & $52.8 \%$ & 0.071 & 0.790 & -0.030 & 0.005 & 0.675 \\
\hline Photo memory score & 6.24 & 6.64 & 4.14 & 0.043 & 0.103 & 0.011 & 0.147 \\
\hline
\end{tabular}




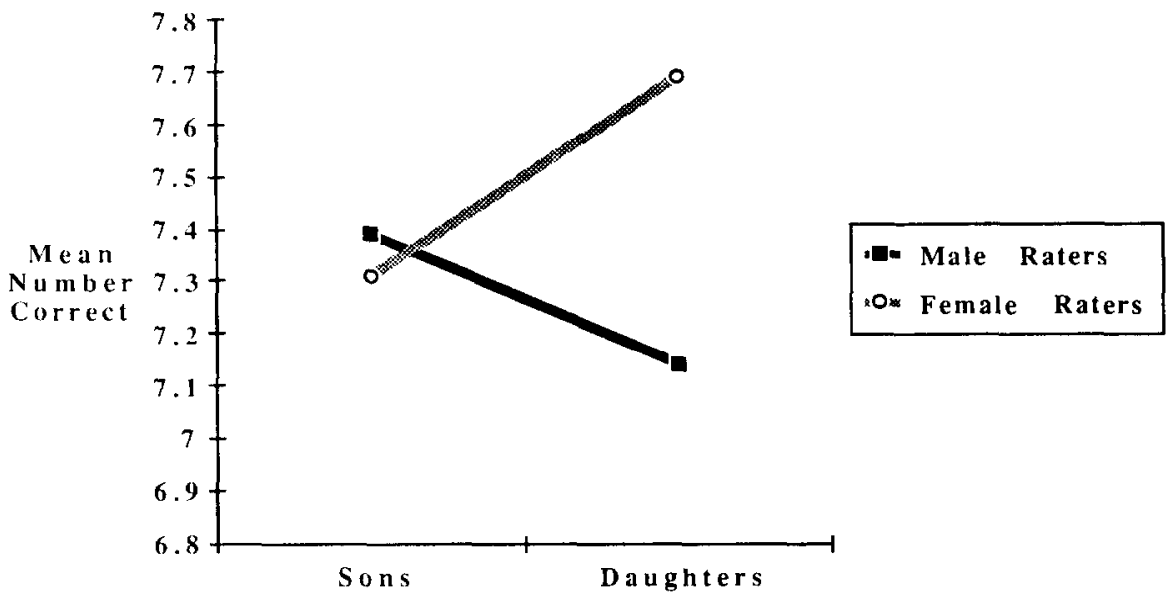

FIGURE 3a. Mean number correct as a function of sex of rater and sex of child.

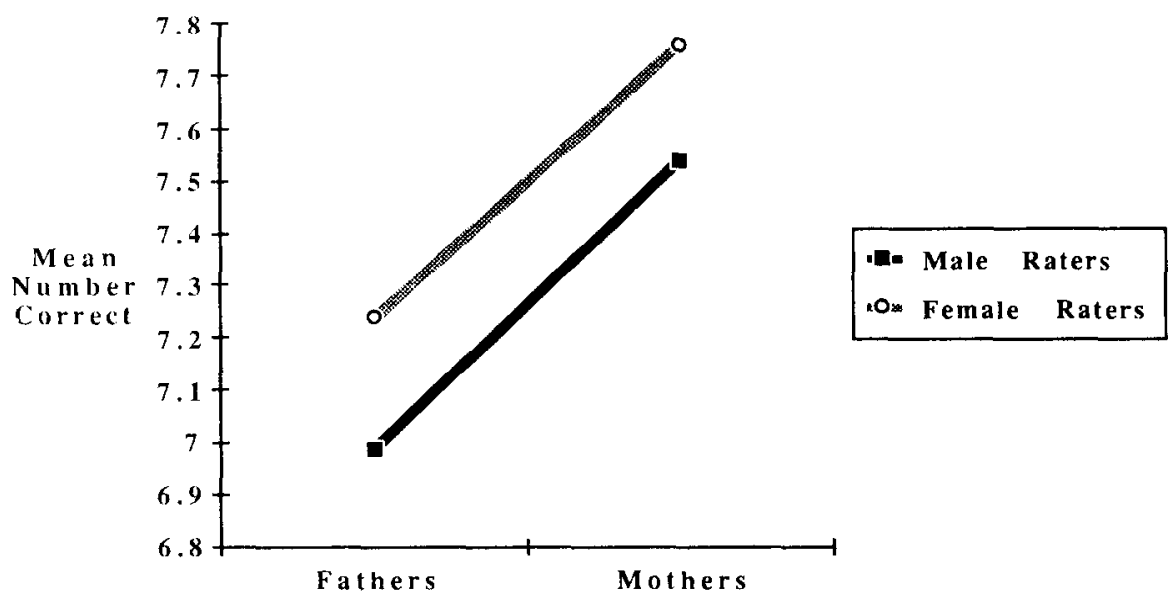

FIGURE 3b. Mean number correct as a function of sex of rater and sex of parent.

had superior ability to recognize faces they had seen earlier in the test $(6.64$ versus 6.24 correct, $F=4.14, p<.043$ ), but this correlated only weakly with the ability to recognize family resemblance. The ability to recognize family resemblance was unrelated to the rater's age, marital status, number of children, number of siblings, or years of education.

\section{DISCUSSION}

Overall, men and women have equal ability to judge family resemblance from photographs of faces. Before attempting to reconcile this main finding 
with the predictions of evolutionary and folk psychology, other results will be discussed.

The biomodal distribution of women's ability to recognize family resemblance might be dismissed as a sampling error, except that it matches the bimodal distribution of women's ability to recognize faces reported by Turkewitz and Ross-Kossak (1984). Our unexpected similar finding for the ability to recognize family resemblance justifies further attempts to characterize these special abilities and the women who possess them.

Both sexes find it easier to identify family resemblance between mothers and children than between fathers and children. If this resulted from mistaken paternity, then at least one item of a supposedly related father/child pair should show many errors, but only one of the three items with nonsignificant item versus total score correlations is a related father/son pair, and this pair was judged to be related by $50 \%$ of raters. A simpler explanation for more accuracy on pairs with mothers is that the facial features of children are more similar to women than men. These findings belie the possibility that children more resemble their fathers than their mothers and thus confirm that the tendency for people to say that babies resemble fathers more than mothers is indeed a result of distortion and deception (Daly and Wilson 1982b).

Each sex is better able to judge family resemblance for children of their own sex. This seems unsurprising, but the absence of a similar tendency for adults is different from McKelvie's report (1981) of superiority in recognizing faces of one's own sex.

The demographic variables were remarkably unrelated to ability to judge family resemblance (Table 2). Contrary to the expectations of many who heard about this study, the ability to judge family resemblance is not influenced by age, number of children, number of siblings, education, or marital status. These results suggest that ability to recognize family resemblance does not improve in any regular way with experience, and that it might be, like memory for faces, a relatively fixed aspect of social intelligence (Kaess and Witryol 1955).

The main finding of this study-that men and women do not differ in ability to judge family resemblance-was predicted neither by evolutionary nor folk psychology. How can this be explained?

The folk psychology prediction seems to be an extrapolation from the generalization that women tend to be better at social tasks. It is curious thet ordinary people would so consistently be wrong about such an aspect of human nature, but growing evidence suggests that such errors are more the rule than the exception (Nisbett and Ross 1980). Folk psychology may not be such a formidable competitor after all, and errors of this sort may offer some excellent opportunities for evolutionists to make predictions that differ from those of folk psychologists.

Consideration of these results in light of the evolutionary prediction is more complicated. We will start with the prediction, made by some, that 
men should definitely be better than women at recognizing family resemblance. First, many of those who made this prediction spent only a few moments on the problem and did not have time to analyze the question carefully. Nonetheless, it is instructive to try to be explicit about why this prediction is wrong. One possbility, often mentioned by critics of sociobiology, is that natural selection is an indeterminate process that does not accomplish everything it might. This caveat, well understood by most evolutionary psychologists, is less useful than it is sometimes portrayed and, in this case, is an explanation of last resort. A similar but more likely flaw in the prediction might result if natural selection simply does not create specialized capacities like the ability to identify family resemblance. Although possible, this seems somewhat unlikely in light of the evidence for the specialized ability to recognize faces. We have not ruled out the possibility that people have other mechanisms to assess relatedness, such as comparisons of voices or patterns of movements.

A likely source of error is the difficulty of taking into account and properly weighting all the factors that affect each sex. Perhaps women gain special advantages from the ability to recognize family resemblance because they maintain kin networks. Perhaps cuckoldry is infrequent enough, and the benefits of detecting it by looking at one's purported children are low enough, that the force of selection on the ability to judge parent/child relatedness would be small. Evolutionists seem to quickly consider the importance of paternity confidence and variance in potential reproductive success to the relative exclusion of other factors.

The most fundamental source of error, however, one that we did not appreciate when starting this study, is failure to analyze exactly how natural selection would shape sexual dimorphism in such a trait. Even if one sex does receive greater benefit from a trait, sex differences would not be shaped by natural selection unless the trait is associated with costs that outweigh the costs of a mechanism to maintain sex differences. The force of selection in creating sexual dimorphism in a trait is a function of the relative benefits and costs of the trait to each sex. Because so many traits, like maintaining a large muscle mass or the ability to lactate, have substantial costs, it is easy to assume that sex differences will arise whenever benefits to the sexes differ. But when the costs of maintaining a mechanism are small, and when a trait offers some benefits to both sexes, sex differencces would be linlikely to result from natural selection.

This research ws made possible by support from the University of Michigan Evolution and Human Behavior Program. Jill Silver gathered much of the data. For helpful consultation and comments on the manuscript, we thank Warren Holmes, David Buss, and other members of the Evolution and Human Behavior Program. Elizabeth Hill provided especially helpful statistical consultation. 


\section{REFERENCES}

Alexander, R.D. The evolution of social behavior. Annual Review of Ecology and Systematics 5: 325-383, 1974

Barkow, J.H. The elastic between genes and culture. Ethology and Sociobiology 10: 111-130, 1989.

Benton, A.L. The neuropsychology of facial recognition. American Psychologist 35: 176-186, 1980.

Berent, S. Functional asymmetry of the human brain in the recognition of faces. Neuropsychologia 15: 829-831, 1977.

Bodamer, J. Die Prosop-agnosie. Archives für Psychiatrie und Nervenkranksheiten 179: 6-54, 1947.

Buss, D.M. Sex differences in human mate selection critera: an evolutionary perspective. In Sociobiology and Psychology, C. Crawford et al. (Eds.). Hillsdale, N.J.: Erlbaum, 1988.

Cosmides. L., and Tooby, J. Evolutionary psychology and the generation of culture, part I: Theoretical considerations. Ethology and Sociobiology 10: 29-50, 1989.

Daly, M., and Wilson, M.I., et al. Male sexual jealousy. Ethology and Sociobiology 3: 11-27, $1982 \mathrm{a}$.

—- and - Whom are babies said to resemble. Ethology and Sociobiology 3: 69-78, 1982b.

- , and - Sex, Evolution, and Behavior. 2nd ed. Boston: Willard Grant Press, 1983.

Deffenbacher, K.A., Carr, T.A., and Leu, J.R. Memory for words, pictures, and faces: retroactive interference, forgetting, and reminiscence. Journal of Experimental Psychology 7: 299-305, 1981.

Diamond, R., and Carey, S. Developmental changes in the representation of faces. Journal of Experimental Child Psychology 23: 1-22, 1977.

Hamilton, W.D. The genetical evolution of social behavior. Journal of Theoretical Biology 7: 1-52, 1964.

Harmon, L.D. The recognition of faces. Scientific American 71-82, 1973.

Hecaen, H., and Angelergues, R. Agnosia for faces (prosopagnosia). Archives of Neurology 7: 92-100, 1962.

Holmes, W.G., and Sherman, P.W. Kin recognition in animals. American Scientist 71: 46-56, 1983.

Kacss, W.A., and Witryol, S.L. Memory for names and faces: a characteristic of social iutelligence? The Journal of Applied Psychology 39: 457-462, 1955.

Kitcher, P. Vaulting Ambition. Cambridge, MA: The MIT Press, 1985.

McKelvie, S.J. Sex differences in memory for faces. The Journal of Psychology 107: 109-125. 1981 .

Nisbett, R., and Ross, L. Human Inference. Englewood Cliffs, NJ: Prentice-Hall, 1980.

Porter, R.H., Cernoch, J.M., and Balogh, R.D. Recognition of neonates by facial-visual characteristics. Pediatrics 74: 501-504, 1984.

Ross-Kossak, P., and Turkewitz, G. Relationship between changes in hemispheric advantag during familiarization to faces and proficiency in facial recognition. Neuropsyologia 22: $471-477,1984$.

Symons, D. The Evolution of Human Sexuality. New York: Oxford University Press, 1979. . Darwin and human nature. Behavioral and Brain Sciences 10: 89, 1987.

. A critique of Darwinian anthropology. Ethology and Sociobiology 10: 131-144, 1987.

Tramel, D., and Damascio, A.R. Knowledge without awareness: a autonomic index of facial recognition by prosopagnosics. Science 228: 1453-1454, 1985.

Turkewitz, G., and Ross-Kossak, P. Multiple modes of right-hemisphere information processing:age and sex differences in facial recognition. Developmental Psychology 20: 95-103, 1984. 